\title{
Increased Oxygen Bioavailability Improved Vigor and Germination of Aged Vegetable Seeds
}

\author{
Guodong Liu ${ }^{1}$ \\ Horticultural Sciences Department, IFAS, University of Florida, 1117 Fifield \\ Hall, Gainesville, FL 32611-0690
}

D. Marshall Porterfield

Department of Agricultural and Biological Engineering, Department of Horticulture and Landscape Architecture and Weldon School of Biomedical Engineering, Purdue University, 225 South University Street, W. Lafayette, IN 47907-2093

\section{Yuncong Li}

Tropical Research and Education Center and Water and Soil Science Department, IFAS, University of Florida, $18905 \mathrm{SW} 280^{\text {th }}$ Street, Homestead, FL 33031

\section{Waldemar Klassen \\ Tropical Research and Education Center and Entomology and Nematology Department, IFAS, University of Florida, 18905 SW 280 th Street, Homestead, FL 33031}

Additional index words. corn, squash, tomato, oxygen fertilizer, seed imbibition, seed oxygen consumption, alcohol dehydrogenase activity

\begin{abstract}
Large and/or aged seeds are prone to hypoxic conditions during germination. Germination of selected vegetable seeds including corn (Zea mays L.), squash (Cucurbita pepo L.), and tomato (Solanum lycopersicum L.) was studied in water with different concentrations of hydrogen peroxide $\left(\mathrm{H}_{2} \mathrm{O}_{2}\right)$ solution ranging from $0,0.06 \%$ to $3.0 \%(\mathrm{v} / \mathrm{v})$ or in aeroponics, all with $0.5 \mathrm{~mm} \mathrm{CaSO}_{4}$. Imbibition, oxygen consumption, proton extrusion, and alcohol dehydrogenase (ADHase) activity of corn seeds were measured gravimetrically, electrochemically, and colorimetrically as appropriate. The results showed that $0.15 \%$ $\mathrm{H}_{2} \mathrm{O}_{2}$ provided the optimum oxygen concentration for seed germination. The germination percentage of aged corn seeds treated with $\mathrm{H}_{2} \mathrm{O}_{2}$ was significantly greater than those without $\mathrm{H}_{2} \mathrm{O}_{2}$ treatment. Corn embryo orientation in relation to a moist substrate also significantly impacted oxygen bioavailability to the embryo and hence ADHase activity. Corn seeds without $\mathrm{H}_{2} \mathrm{O}_{2}$ imbibed significantly more slowly than those with oxygen fortification by $0.15 \% \mathrm{H}_{2} \mathrm{O}_{2}$. Increased oxygen bioavailability improved the metabolism of the seeds, which extruded 5-fold more protons from the embryos. Each treated embryo consumed twice the amount of oxygen as compared with the untreated one and likewise for treated and untreated endosperms. Increased oxygen bioavailability may be used to improve production of the tested crops. The results from this research imply that consideration should be given to including oxygen fortification in seed coatings for aged seeds and for large seeds regardless of age. The artificial provision of bioavailable oxygen might be effective in rescuing the germplasm in aged seeds in plant breeding and in crop production.
\end{abstract}

A high seed germination percentage is a prerequisite for successful commercial vegetable production. Seed vigor, appropriate

Received for publication 4 Sept. 2012. Accepted for publication 15 Oct. 2012.

This project was financially supported by the U.S. Department of Agriculture, Grant No. NRICGP 2001-35100-10751.

We gratefully acknowledge Illinois Foundation Seeds Inc. for providing the corn seeds. We thank Professor Daniel Cantliff and Professor Edward Hanlon at the University of Florida for their valuable comments and suggestions.

${ }^{1}$ To whom reprint requests should be addressed; e-mail guodong@ufl.edu. temperature, and oxygen and water bioavailability are key factors in high percentages of seed germination (Bewley and Black, 1994). Seed vigor and bioavailable oxygen are closely associated. Particularly, aged or large seeds are especially prone to lack of oxygen bioavailability (Geigenberger et al., 2000). However, the sufficiency of oxygen bioavailability is not easily secured in soil or water. For example, water saturated with air contains $\approx 250 \mu \mathrm{M}$ oxygen (Lide, 1998), which is too little to supply sufficient bioavailable oxygen to support the germination of relatively large or aged seeds. In fact, seed hypoxia caused by flooding is a worldwide problem (Jackson et al., 2009) and a detrimental factor in plant growth and development of vegetable (Edelstein et al., 1995). The rainy periods in the spring often introduce much uncertainty into growers' decision-making process pertaining to corn and vegetable planting. Because a corn seed has a volume six to 10 times larger than that of wheat or rice, corn seed is more likely to suffer from oxygen deficiency than the latter two species as measured (data not shown). Specific surface area is a material property of solids, which measures the total surface area per unit of bulk volume. It is defined by surface area divided by the volume (units of $\mathrm{m}^{2} / \mathrm{m}^{3}$ ). Specific surface area of corn seeds is only $0.1 \%$ to $0.5 \%$ that of the other two types of seeds based on our calculations. Additionally, waterlogging (i.e., oxygen bioavailability deficiency) sometimes causes up to $50 \%$ loss of crop yield (Dennis et al., 2000). Such yield losses have usually resulted from failure both of seed germination and plant growth and development.

Oxygen bioavailability deficiency can be caused by different factors including waterlogging or aging and may be responsible for failures of seed germination. Oxygen bioavailability is, therefore, a significant factor in determining seed vigor and seed germination (Bewley and Black, 1994). Early aging or degeneration of seeds may also result in losses of seed vigor and vegetable yield as a result of unfavorable cultivation or storage conditions (Hong, 2001). Heavy rainfall after sowing often causes oxygen deficiency in the seedbed sufficiently severe to hamper emergence (Håkansson et al., 2012). Aged seeds are characterized by poor germination and slow post-germination growth, and they have low plasma membrane $\mathrm{H}^{+}$-ATPase activity. This low enzyme activity may partially explain poor germination and low post-germination root elongation and growth of seedlings developed from aged seeds (Sveinsdottir et al., 2009). The essence of slow and/or low germination percentage is the retardation of biochemical and physiological reactions in aged seeds. Energetically, such retardation is related to a deficiency of active chemical energy, adenosine triphosphate (ATP), because aged seeds may have reduced content of nonsymbiotic hemoglobins. These hemoglobins act in plants to maintain the energy status of cells in hypoxic conditions such as during flooding, and they accomplish this by increasing substrate-level phosphorylation. Nonsymbiotic hemoglobins likely sequester oxygen in hypoxic environments, providing a source of oxygen to oxidize NADH to produce ATP for cell growth and development (Sowa et al., 1998). ATP deficiency may be common both in aged and flooded seeds. Therefore, new technologies are needed to coat large seeds like corn or other vegetable seeds with oxygen fertilizers to improve seed germination and crop success. Such technologies may be also advantageous in accelerating crop breeding for rescuing rare plant germplasm from aged or improperly stored seeds. However, there are no published accounts of an adequate understanding of the relationship between 
oxygen bioavailability and seed germination, and no effective methods are available for improving germination of large seeds and/or aged seeds.

The objectives of this research were to 1) clarify the relationship between the concentration of bioavailable oxygen in the liquid imbibed by the germinating seed and seed vigor; 2) define the optimum oxygen bioavailability for improving germination percentages of aged and waterlogged seeds; and 3) provide a method for rescuing plant germplasm from aged or improperly stored seeds for use in plant breeding programs.

\section{Materials and Methods}

Seeds. Corn (Zea mays L.) seeds (genotype, 'FR27 × FRM017') were kindly provided by Illinois Foundation Seeds Inc., Tolono, IL. Two different age categories of seeds were used: in one, the seeds were three years old and in the other, the seeds were less than one year old. Seeds of squash (Cucurbita pepo L.) and tomato (Solanum lycopersicum L.) genotypes were both collected from a breeding research program at the University of Florida. The squash seeds (genotype, 125X) were four years old and the tomato seeds (genotype, 6132-HBK) were six years old, respectively. The seeds had been stored at ambient room temperature $\left(24 \pm 1{ }^{\circ} \mathrm{C}\right)$ and humidity $(78.3 \% \pm 6.9 \%)$. The seed lots are all pure lines.

Aeroponics treatment for corn seeds. Twenty-five liters of deionized (DI) water adjusted to $0.5 \mathrm{~mm} \mathrm{CaSO}_{4}$ (Lynch et al., 1987; Nadeem et al., 2012) were poured into a 38 -L square tank $\left(61 \times 61 \times 30 \mathrm{~cm}^{3}\right)$ (Growgenie, San Jose, CA). Calcium is essential to the intactness and selectivity of biological membranes. Aged seeds have very fragile biological membranes. To protect the membrane, $0.5 \mathrm{~mm} \mathrm{CaSO}_{4}$ was added. The tank was covered with a 5 -mm thick plastic sheet containing 60 evenly spaced holes, each $48 \mathrm{~mm}$ in diameter. One plastic basket $(50 \mathrm{~mm}$ high and external diameter of $55 \mathrm{~mm}$ at the top and $37 \mathrm{~mm}$ at the bottom) was suspended in the space above the water with a wire secured through a hole in the cover. Six corn seeds were placed into each basket. A 24-W electric pump (Danner Mfg. Inc., Islandia, NY) was installed on the tank bottom and a nozzle was attached to the pump and positioned in the center of the tank above the surface of the water. The nozzle created a mist for treating the seeds in the baskets. The tank was put in a growth chamber (Percival Scientific, Inc., Perry, IA) at $25 \pm 1{ }^{\circ} \mathrm{C}$ and 16-h photoperiod with fluorescent lamps (intensity programmed to $1250 \mu \mathrm{mol} \cdot \mathrm{m}^{-2} \cdot \mathrm{s}^{-1}$ of light irradiance) and $22 \pm 1{ }^{\circ} \mathrm{C}$ and 8 -h scotoperiod for $3 \mathrm{~d}$. The numbers of germinated and non-germinated seeds were always counted at $48 \mathrm{~h}$ after treatment.

Hydrogen peroxide treatments of all seeds. Thirty corn seeds were soaked for $24 \mathrm{~h}$ in $50 \mathrm{~mL}$ of $0.5 \mathrm{~mm} \mathrm{Ca}\left(\mathrm{as} \mathrm{CaSO}_{4}\right)$ containing
$0.06 \%, 0.08 \%, 0.10 \%, 0.15 \%, 0.3 \%$, or $3.0 \%$ $(\mathrm{v} / \mathrm{v}) \mathrm{H}_{2} \mathrm{O}_{2}$ in a $95 \times 15-\mathrm{mm}$ petri dish at room temperature $\left(25 \pm 1{ }^{\circ} \mathrm{C}\right)$. The seeds were carefully rinsed four times with DI water to remove the remaining $\mathrm{H}_{2} \mathrm{O}_{2}$. Next in another $95 \times 15-\mathrm{mm}$ petri dish, these rinsed seeds were placed on a napkin saturated with $0.5 \mathrm{~mm} \mathrm{CaSO}_{4}$ solution. The petri dish was sealed with parafilm to retain the moisture. Squash and tomato seeds were treated in exactly the same manner as the corn seeds but with or without $0.15 \% \mathrm{H}_{2} \mathrm{O}_{2}$, because the assay data of corn seeds had proved that $0.15 \% \mathrm{H}_{2} \mathrm{O}_{2}$ worked best and squash and tomato seeds were assumed to respond similarly.

Aeration treatment for corn seeds. Thirty seeds were put into a plastic basket of the same type as described previously, which was immersed in $300 \mathrm{~mL} 0.5 \mathrm{~mm} \mathrm{CaSO}_{4}$ in a $500-\mathrm{mL}$ beaker. The solution was aerated for $24 \mathrm{~h}$. The seeds were placed in a $95 \times$ $15-\mathrm{mm}$ petri dish on a napkin saturated with $0.5 \mathrm{~mm} \mathrm{CaSO}_{4}$ solution.

Imbibition measurement. Ten corn seeds were put in a vial with $20 \mathrm{~mL}$ of the soaking $0.5 \mathrm{~mm} \mathrm{CaSO} 4$ solution with or without $0.15 \% \mathrm{H}_{2} \mathrm{O}_{2}$ at room temperature $\left(25 \pm 1{ }^{\circ} \mathrm{C}\right)$. The weight of the seeds was determined gravimetrically every $24 \mathrm{~h}$ for $96 \mathrm{~h}$ after unbound moisture had been removed from the seed surface with an absorbent napkin.

Microelectrode fabrication. Ten-centimeter lengths of untreated $1.5-\mathrm{mm}$ diameter borosilicate glass capillaries (cat no. TW150-4; World Precision Instruments, Sarasota, FL) were each pulled into two micropipettes through a Sutter P-97 micropipette puller (Sutter Instrument Company, Novato, CA) at $545^{\circ} \mathrm{C}$. The freshly pulled micropipettes were silanized at $200{ }^{\circ} \mathrm{C}$ with $\mathrm{N}, \mathrm{N}$-dimethyltrimethylslylamine according to Smith's method (Smith et al., 1999). Micropipettes were backfilled with $\mathrm{H}^{+}$probe backfilling solution of $50 \mathrm{~mm} \mathrm{KCl}$ and $50 \mathrm{~mm} \mathrm{HK}_{2} \mathrm{PO}_{4}$. Then hydrogen ionophore I-Cocktail B (cat no. 95293; Fluke Chemika, Switzerland) was drawn into the tip with a minimal negative pressure and viewed by a binocular compound microscope (Smith et al., 1999).

Measurement of net ion fluxes. Forty-five grams of Sylgard 184 silicone elastomer and 5 g Sylgard 184 curing agent (Dow Corporation) were poured onto the bottom of a $10-\mathrm{cm}$ diameter Pyrex ${ }^{\circledR}$ dish to secure the treated seed for scanning. One seed was secured on the Sylgard in the center of the dish with four to five Minucie stainless steel needles. Microelectrodes were calibrated before and after each experiment. Calibrations were done in standard $\mathrm{pH}$ 6, 7, and 8 solutions (Fisher Scientific, Pittsburgh, PA) at $25{ }^{\circ} \mathrm{C}$. The Nernst slopes (in $\mathrm{mV} /$ decade) were equal to 59. After calibration, the microelectrode was positioned both on the embryo and on the endosperm of the targeted seed, respectively. Then, a $100 \mu \mathrm{m} \times 100-\mu \mathrm{m}$ area of each embryo and endosperm was scanned by means of the self-referencing ion selective electrode (Smith et al., 1999). Ten embryos and endosperms were scanned in each treatment. Extrusions of protons were always calculated and averaged based on the 10 measurements.

Measurements of oxygen consumption. The corn seeds were soaked in $0.5 \mathrm{mM} \mathrm{CaSO}_{4}$ solution with $0 \%$ or $0.15 \% \mathrm{H}_{2} \mathrm{O}_{2}$ for $1 \mathrm{~d}$ before any measurements were made. Each seed was secured on Sylgard as described previously. Platinum-iridium oxygen electrodes were used. The microelectrode was calibrated before and after each experiment. Calibrations were performed in DI water saturated with air as $21 \%$ oxygen concentration and in DI water through which nitrogen gas had been bubbled for $30 \mathrm{~min}$ to reduce the oxygen concentration to $0 \%$ (Wu et al., 2002). Scans were done on 10 embryos and on 10 endosperms in each treatment. Oxygen consumption per embryo or endosperm was always calculated and averaged based on the 10 measurements.

Alcohol dehydrogenase activity. ADHase activity levels were measured in corn embryos held at different concentrations of bioavailable oxygen for $48 \mathrm{~h}$ after germination at $25 \pm 1{ }^{\circ} \mathrm{C}$. Before germination, the corn seeds were soaked in $0.5 \mathrm{~mm} \mathrm{CaSO}_{4}$ solution, in aeroponics with $0.5 \mathrm{~mm} \mathrm{CaSO}_{4}$, or in $0.15 \%$ $\mathrm{H}_{2} \mathrm{O}_{2}$ with $0.5 \mathrm{~mm} \mathrm{CaSO}_{4}$ for $24 \mathrm{~h}$. After treatment each corn seed was cut into two halves so the embryo was also cut into halves. Four embryo halves were homogenized in an extraction buffer composed of $50 \mathrm{~mm}$ Tris$\mathrm{HCl}(\mathrm{pH} 8.0), 1 \mathrm{~mm}$ EDTA, $0.5 \mathrm{mg} \cdot \mathrm{mL}^{-1}$ DTT, and $12 \mu \mathrm{M} \beta$-mercaptoethanol. The extraction solution of the ADHase enzyme was centrifuged twice at $4 \pm 0.1{ }^{\circ} \mathrm{C}$ at $15,000 \mathrm{rpm}$ for $5 \mathrm{~min}$ : first to separate the corn oil on the top and the pellet on the bottom and then to get the ADHase supernatant used for ADHase measurement. The ADHase activity assay was performed according to the procedures described in Xie and Wu (1989). One hundred microliters of enzyme solution and $900 \mu \mathrm{L}$ of reaction solution composed of $50 \mathrm{~mm}$ Tris- $\mathrm{HCl}$ (pH 9.0), $1 \mathrm{~mm}$ EDTA, and $1 \mathrm{~mm}$ NAD were incubated in $1.5-\mathrm{mL}$ microcentrifuge tubes in a water bath at $30{ }^{\circ} \mathrm{C}$ for 3 min. Then, $100 \mu \mathrm{L} 15 \%$ ethanol and the previously described $1000 \mu \mathrm{L}$ enzyme and reaction solution were added directly to a cuvette. After a reaction time of $1 \mathrm{~min}$ in the cuvette, a reading at $340 \mathrm{~nm}$ was made with a spectrophotometer (DU 64; Beckman Instruments, Fullerton, CA) to determine the concentration of NADH. The ADHase activity was calculated and averaged from nine measurements. A unit of ADHase activity is defined as the production of $1 \mathrm{nmol} \mathrm{NADH} /$ min. $\mathrm{mg}^{-1}$ protein.

Protein measurement. Protein contents of the samples were colorimetrically determined according to Lowry's method (Lowry et al., 1951; Peterson, 1977). Ten microliters of supernatant were mixed with $990 \mu \mathrm{L}$ Lowry A [equal volumes of copper-tartrate-carbonate solution consisting of $0.1 \% \mathrm{CuSO}_{4} \cdot 5 \mathrm{H}_{2} \mathrm{O}$, $0.2 \% \mathrm{KNa}$-tartrate, and $10 \% \mathrm{NaCO}_{3} ; 10 \%$ sodium dodecyl sulfate $(95 \%$, Sigma \# L$5750) ; 0.80 \mathrm{~N} \mathrm{NaOH}$ and DI water], and $15 \mathrm{~min}$ later, $500 \mu \mathrm{L}$ Lowry B [one part of $2.0 \mathrm{~N}$ 
Folin \& Ciocalteu's Phenol Reagent Solution (Sigma \# F-9252) diluted in five parts of DI water] was added. Bovine serum albumin (Sigma \# A-2153) was used to prepare the standards (Arcan and Yemsnicioğlu, 2007; Harris, 1987). All measurements were repeated three times.

Statistical analysis. The data were analyzed by one-way analysis of variance (SAS Institute, 2009). Results were considered significant at $P<0.05$. After running the SAS program, the critical ranges (least significant difference $_{2,0.05}$ ) of Duncan's multiple range test were used to identify significantly different means (Hubbard, 2001).

\section{Results}

Effects of different oxygen bioavailabilities on germination percentages of corn seeds. The germination percentage of corn seeds treated with $\mathrm{H}_{2} \mathrm{O}_{2}$ was significantly greater than that with aerated water but without $\mathrm{H}_{2} \mathrm{O}_{2}$. Among all of the treatments with $\mathrm{H}_{2} \mathrm{O}_{2}$, germination percentages with $0.15 \%$ and $0.30 \% \mathrm{H}_{2} \mathrm{O}_{2}$ were significantly higher than in the other treatments. There was no significant difference between $0.15 \% \mathrm{H}_{2} \mathrm{O}_{2}$ and $0.30 \% \mathrm{H}_{2} \mathrm{O}_{2}$ (Fig. 1). This effect of oxygen fortification from $\mathrm{H}_{2} \mathrm{O}_{2}$ on seed germination indicates that, up to a point, i.e., $0.15 \%$ in this study, the higher the concentration of bioavailable oxygen used, the greater the seed germination percentage. There is a sigmoid relationship $\left(r^{2}=0.81\right)$ between $\mathrm{H}_{2} \mathrm{O}_{2}$ concentration $(\%)$ and corn seed germination $(\mathrm{G})$ in this range of tested
$\mathrm{H}_{2} \mathrm{O}_{2}$ concentrations from $0.06 \%$ to $3.0 \%$ as shown in Eq. (1):

$$
\mathrm{G}(\%)=\frac{93}{1+\mathrm{e}^{-\frac{\left[\mathrm{H}_{2} \mathrm{O}_{2}\right]+0.0185}{0.0382}}}
$$

Nevertheless, this effect suggests that concentrations of bioavailable oxygen somewhat greater than $0.3 \%$ may be detrimental to corn seed germination and subsequent development. For example, the average length of the roots from seeds treated with $3 \% \mathrm{H}_{2} \mathrm{O}_{2}$ was only $6.8 \pm 1.7 \mathrm{~mm} 3 \mathrm{~d}$ after germination. In contrast, the corresponding average root length was $34.8 \pm 1.7 \mathrm{~mm}$ in the $0.15 \%(\mathrm{v} / \mathrm{v})$ $\mathrm{H}_{2} \mathrm{O}_{2}$ treatment.

The treatment with $0.15 \% \mathrm{H}_{2} \mathrm{O}_{2}$ resulted in the greatest germination percentage of both aged and unaged seeds, whereas corresponding germination percentages with the water treatment germinated poorly (Fig. 2). Aged seeds are defined as those seeds that were stored at room temperature for more than two years and otherwise are considered as unaged seeds. The germination percentages of both aged and unaged seeds seemed to be closely correlated with the concentration of bioavailable oxygen. Moreover, Figure 2 shows that when treated with $0.15 \% \mathrm{H}_{2} \mathrm{O}_{2}$ and $\mathrm{CaSO}_{4}$ or aeroponics with $\mathrm{CaSO}_{4}$, the differences in the germination percentages between the aged and unaged corn seeds became insignificant.

However, in the 0.5-mm $\mathrm{CaSO}_{4}$ soaking treatment, which had the lowest concentration of bioavailable oxygen, the germination percentage of unaged seeds was more than 2.5 -fold greater than that of aged seeds
(76.7\% $\pm 15.3 \%$ of unaged seeds and $30.0 \% \pm$ $11.5 \%$ of aged seeds). The aged seeds were much more sensitive to the concentration of bioavailable oxygen than the unaged seeds.

At $24 \mathrm{~h}$, all of the unaged corn seeds had begun to germinate in both the $0.15 \% \mathrm{H}_{2} \mathrm{O}_{2}$ and the aeroponics treatments but only few seeds had begun to germinate in the DI water soaking treatment. Further after $72 \mathrm{~h}$, each seed in the oxygen-sufficient $0.15 \% \mathrm{H}_{2} \mathrm{O}_{2}$ treatment had both a shoot and a root 1 to $2 \mathrm{~cm}$ in length, but only one-third of the seeds in the $0.5-\mathrm{mm} \mathrm{CaSO}_{4}$ treatment had begun to germinate (Fig. 3).

Seed position also impacted germination significantly. Keeping corn embryo up to air resulted in a 3.1-fold greater seed germination percentage than positioning the seed with the embryo beneath and away from air (Fig. 4). This result indicates that the corn seeds in water were lacking oxygen and hence their germination was retarded.

Effects of oxygen bioavailability on germination percentages of selected vegetable seeds. Aged seeds had very poor germination percentages regardless of crop type but oxygen fortification with $0.15 \% \mathrm{H}_{2} \mathrm{O}_{2}$ significantly improved the germination percentages of the selected vegetable seeds (Fig. 5).

Rate of imbibition by corn seeds. From the first day, the imbibition rate of seeds in the $0.15 \% \mathrm{H}_{2} \mathrm{O}_{2}$ treatment was always $11 \%$ to $13 \%$ greater that than in the water treatment. The kinetics of seed imbibition indicate that cumulative water uptake of corn seeds in the $0.15 \% \mathrm{H}_{2} \mathrm{O}_{2}$ treatment was $14 \%$ to $20 \%$ faster than that in the water treatment. These

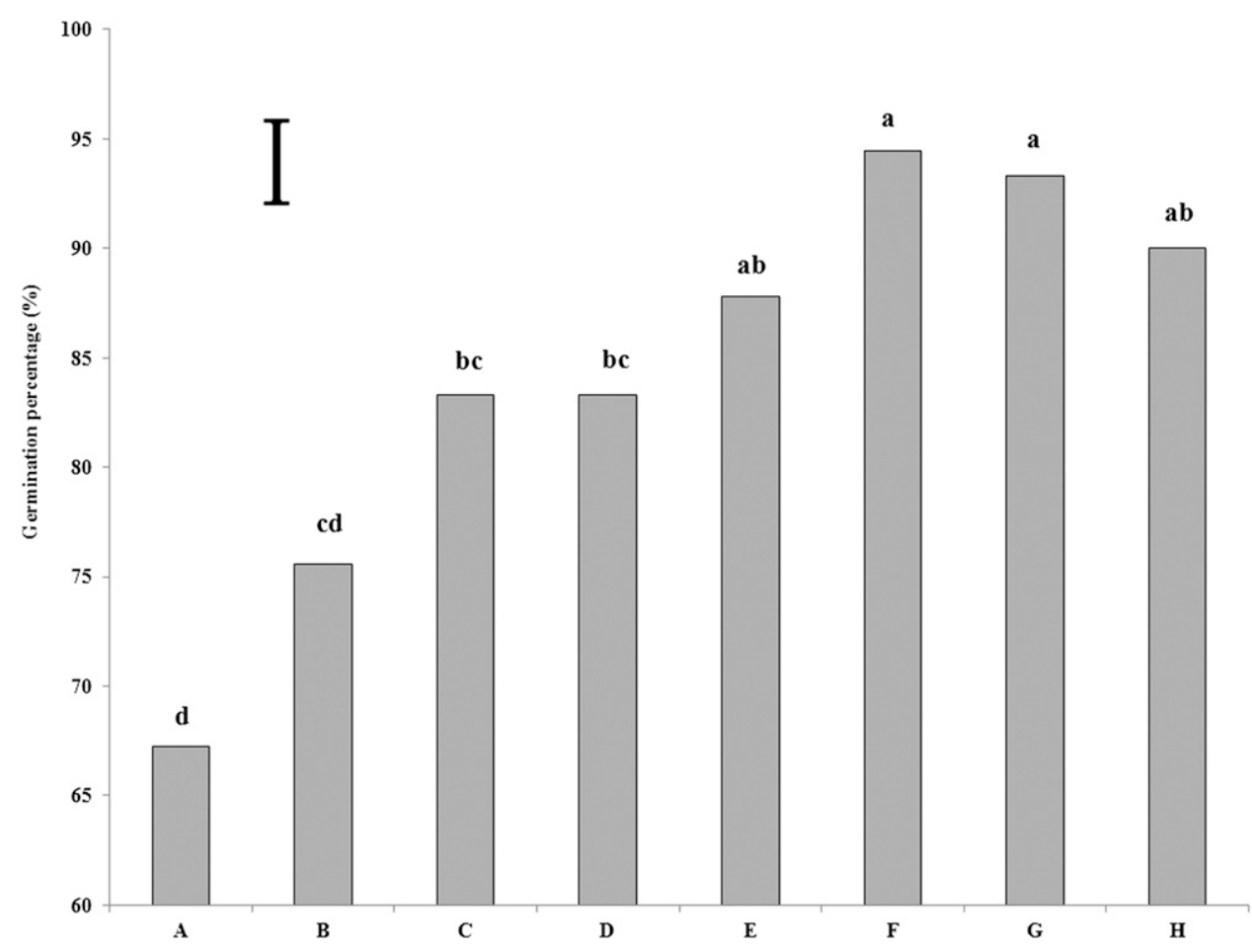

Fig. 1. Germination percentages of corn seeds at $48 \mathrm{~h}$ after treatment with different concentrations of bioavailable oxygen. (A) Aeration; (B) aeroponics; (C) $0.06 \%$; (D) $0.08 \%$; (E) $0.10 \%$; (F) $0.15 \%$; (G) $0.30 \%$; (H) $3.00 \%$ hydrogen peroxide $\left(\mathrm{H}_{2} \mathrm{O}_{2}\right)$. The bars sharing the same letter are not significantly different. Vertical bars indicate least significant difference at $\alpha=0.05$. 


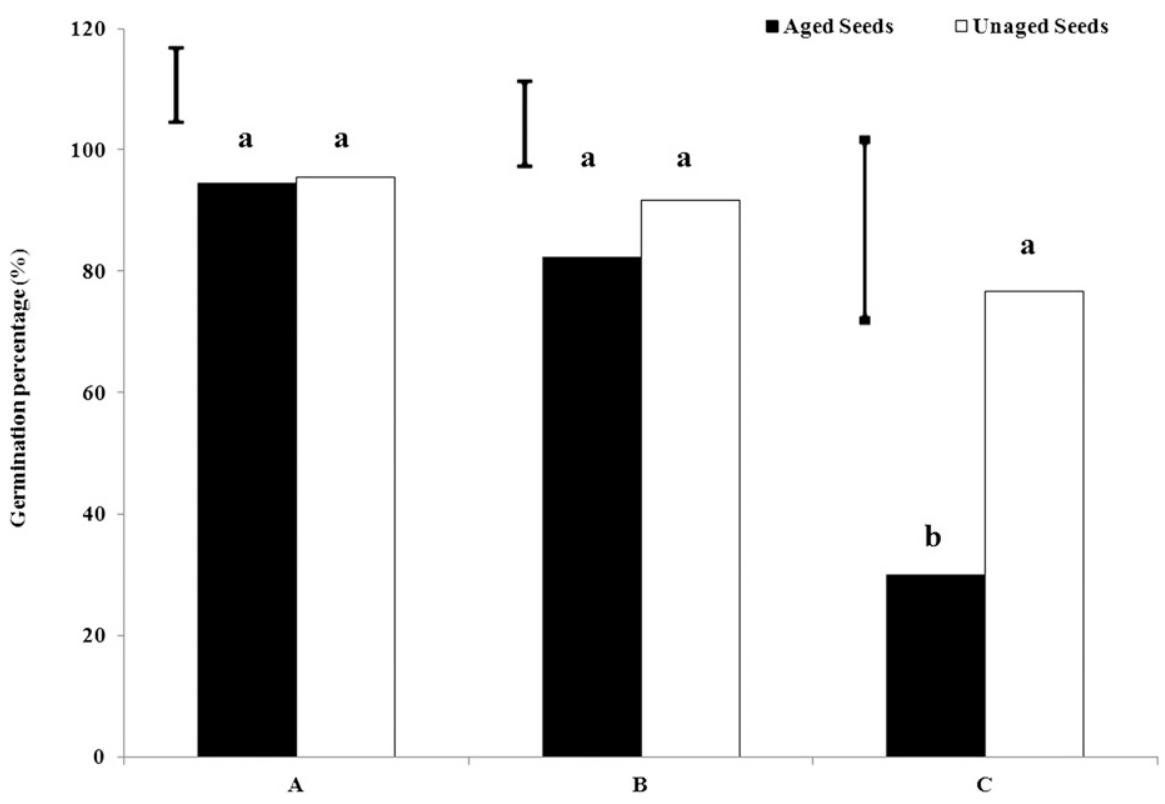

Fig. 2. Effects of oxygen fortification with hydrogen peroxide $\left(\mathrm{H}_{2} \mathrm{O}_{2}\right)$ on seed germination of three-yearold and new corn seeds. (A) Seeds were soaked in $0.15 \% \mathrm{H}_{2} \mathrm{O}_{2}$ with $0.5 \mathrm{~mm} \mathrm{CaSO}_{4}$ for $24 \mathrm{~h}$; (B) seeds were treated in aeroponics with $0.5 \mathrm{~mm} \mathrm{CaSO}_{4}$ for $24 \mathrm{~h}$; (C) seeds soaked in $0.5 \mathrm{~mm} \mathrm{CaSO}_{4}$ solution for $24 \mathrm{~h}$. Vertical bar indicates least significant difference at $\alpha=0.05$.

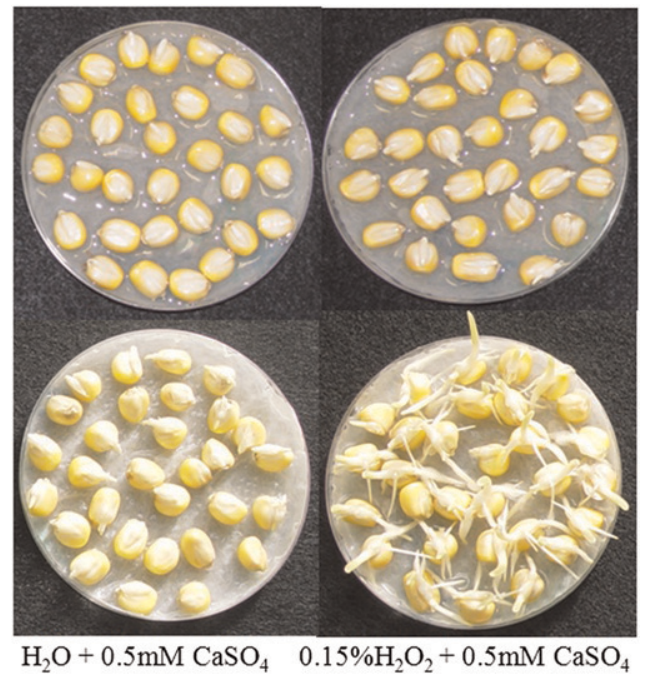

Fig. 3. Effect of bioavailable of oxygen fortification on the germination percentage of new corn seeds. Seeds in the two dishes on the left were treated with deionized (DI) water containing $0.5 \mathrm{~mm} \mathrm{CaSO}_{4}$ and those on the right were treated with $0.15 \%$ hydrogen peroxide $\left(\mathrm{H}_{2} \mathrm{O}_{2}\right)$ as an oxygen fertilizer with $0.5 \mathrm{~mm} \mathrm{CaSO}_{4}$ at $24 \mathrm{~h}$ (in the upper pairs). At $72 \mathrm{~h}$ (in the lower pairs), the root was emerging from only a few seeds in the DI water treatment, whereas in the $\mathrm{H}_{2} \mathrm{O}_{2}$ treatment, a 1- to 2-cm long root and a shoot were growing out of all of the seeds.

data demonstrate that the increased bioavailability of oxygen accelerates water uptake by corn seeds (Fig. 6).

The cumulative water uptake (CWU) per seed can be fitted with time ( $t$, day) in the following formula:

$$
C W U=\frac{a}{1+\left(\frac{t}{t_{0}}\right)^{b}}
$$

where $a$ is the maximum CWU value per corn seed and $b$ is the constant of water uptake rate by the seed with or without $\mathrm{H}_{2} \mathrm{O}_{2}$, and $\mathrm{t}_{0}$ is the initiation time of seed imbibition in this study. Thus, the CWU value of the seed can be calculated by using Eq. (3) with $\mathrm{H}_{2} \mathrm{O}_{2}$ or Eq. (4) without $\mathrm{H}_{2} \mathrm{O}_{2}$.

The CWU value per seed treated with $0.15 \% \mathrm{H}_{2} \mathrm{O}_{2}$ :

$$
\begin{aligned}
\mathrm{CWU}_{\mathrm{H}_{2} \mathrm{O}_{2}} & =\frac{192.1}{1+\left(\frac{\mathrm{t}}{0.5146}\right)^{-1.5118}} \\
& =\frac{192.1}{1+\left(\frac{0.5146}{\mathrm{t}}\right)^{1.5118}} \\
r^{2} & =0.99
\end{aligned}
$$

The CWU value per seed treated with $\mathrm{H}_{2} \mathrm{O}$ :

$$
\begin{aligned}
\operatorname{CWU}_{\mathrm{H}_{2} \mathrm{O}} & =\frac{180.9}{1+\left(\frac{\mathrm{t}}{0.4744}\right)^{-1.1206}} \\
& =\frac{180.9}{1+\left(\frac{0.4744}{\mathrm{t}}\right)^{1.1206}} \\
r^{2} & =0.99
\end{aligned}
$$

Based on Eq. (2), $a$ is the maximum CWU value when $t$ is infinite. Therefore, Eqs. (3) and (4) define the maximum CWU of the seeds with or without $\mathrm{H}_{2} \mathrm{O}_{2}$ as 192.1 or 180.9 , respectively. These calculations showed that the seed with $\mathrm{H}_{2} \mathrm{O}_{2}$ imbibed $11.2 \mathrm{mg}$ more water per seed than that without $\mathrm{H}_{2} \mathrm{O}_{2}$.

Based on mathematics, the derivative of Eq. (3) or (4) is the rate of water uptake (WUR) of the corn seed with or without $\mathrm{H}_{2} \mathrm{O}_{2}$.

$$
\begin{aligned}
\mathrm{WUR}_{\mathrm{H}_{2} \mathrm{O}_{2}}= & 1540.7 \mathrm{t}^{-2.5118}+282.2 \mathrm{t}^{-1} \\
& +408.0 \mathrm{t}^{-0.5118} \\
\mathrm{WUR}_{\mathrm{H}_{2} \mathrm{O}}= & 958.4 \mathrm{t}^{-2.1206}+213.6 \mathrm{t}^{-1} \\
& +221.8 \mathrm{t}^{-0.1206}
\end{aligned}
$$

The $\mathrm{H}_{2} \mathrm{O}_{2}$ treatment greatly facilitated and increased the seed imbibition. For example, based on Eqs. (5) and (6), the WUR of the seed was $60.1 \%$ faster in the $\mathrm{H}_{2} \mathrm{O}_{2}$ treatment than in the DI water treatment on Day 1.

Consumption of oxygen by corn seeds. The oxygen consumption rate of both the embryo and the endosperm of a corn seed that had been soaked for $24 \mathrm{~h}$ to the $0.15 \% \mathrm{H}_{2} \mathrm{O}_{2}$ treatment was $\approx 2$-fold greater than the corresponding rate in the DI water treatment. The oxygen consumption rate of embryos in the DI water treatment seemed slightly faster than that of the endosperm in the $0.15 \% \mathrm{H}_{2} \mathrm{O}_{2}$ treatment (Fig. 7). Thus, the lowest oxygen consumption rate of embryos was greater than the highest oxygen consumption rate of endosperms, regardless of the treatments involved.

Influx and efflux of protons with respect to corn seed embryos and endosperms. Proton flux is characteristic of metabolism in living organisms. Figure 8 demonstrates that oxygen bioavailability determines the direction of flux of protons. Under hypoxia, both embryos and endosperms imbibed protons (Yan et al., 1998) and, hence, net decreases of protons were measured in the seeds. However, in corn seeds in the $0.15 \% \mathrm{H}_{2} \mathrm{O}_{2}$ treatment, strong proton efflux occurred in both the embryos and the endosperms. Figure 8 also shows that metabolic activity of developing embryos is always much greater than that of endosperms irrespective of the treatment.

Alcohol dehydrogenase activities of corn embryos. It is well known that ADHase enables plants to adapt to hypoxic stress. Figure 9 shows that $\mathrm{H}_{2} \mathrm{O}_{2}$, aeroponics, and orientation of the embryo in the corn seed strongly affected the activity of the ADHase. When corn seeds had lain with the embryos beneath 


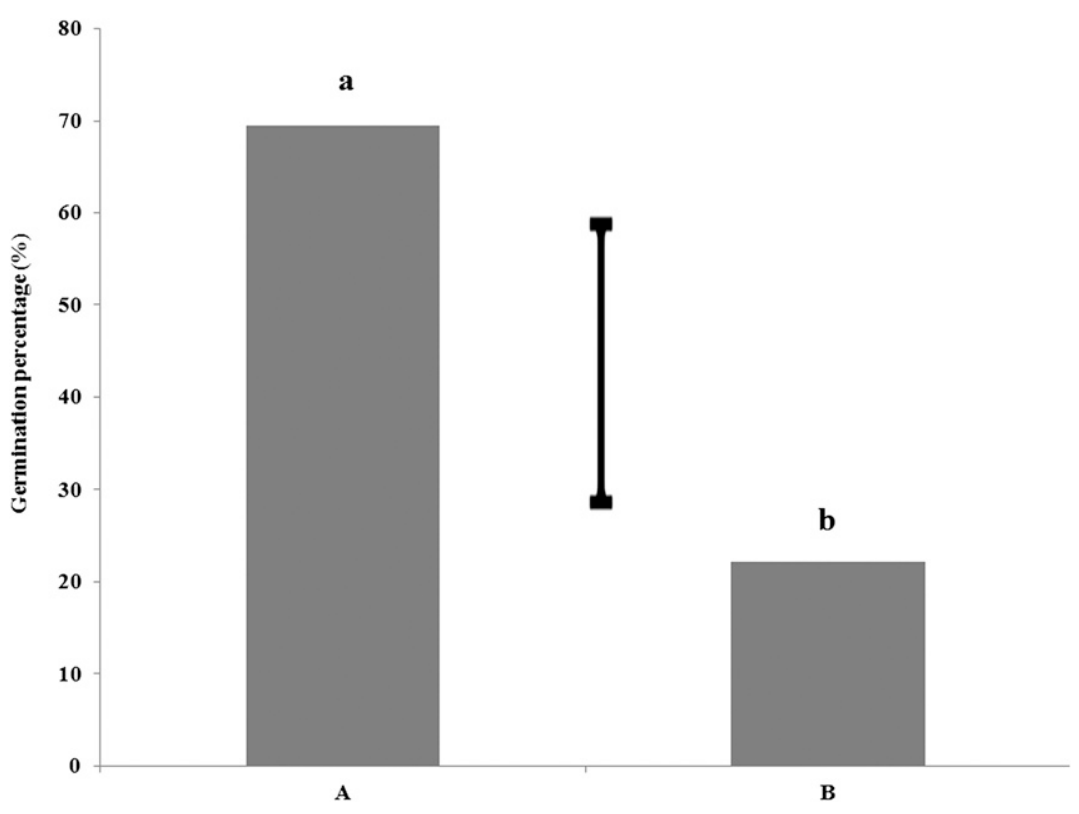

Fig. 4. Effect of seed position on germination of new corn seeds. (A) Each seed was soaked in deionized (DI) water with $0.5 \mathrm{~mm} \mathrm{CaSO}_{4}$ for $24 \mathrm{~h}$ and then positioned with the embryo facing up to the air; (B) each seed was soaked in DI water with $0.5 \mathrm{~mm} \mathrm{CaSO}_{4}$ for $24 \mathrm{~h}$ and positioned with the embryo beneath and away from the air. Vertical bar indicates least significant difference at $\alpha=0.05$.
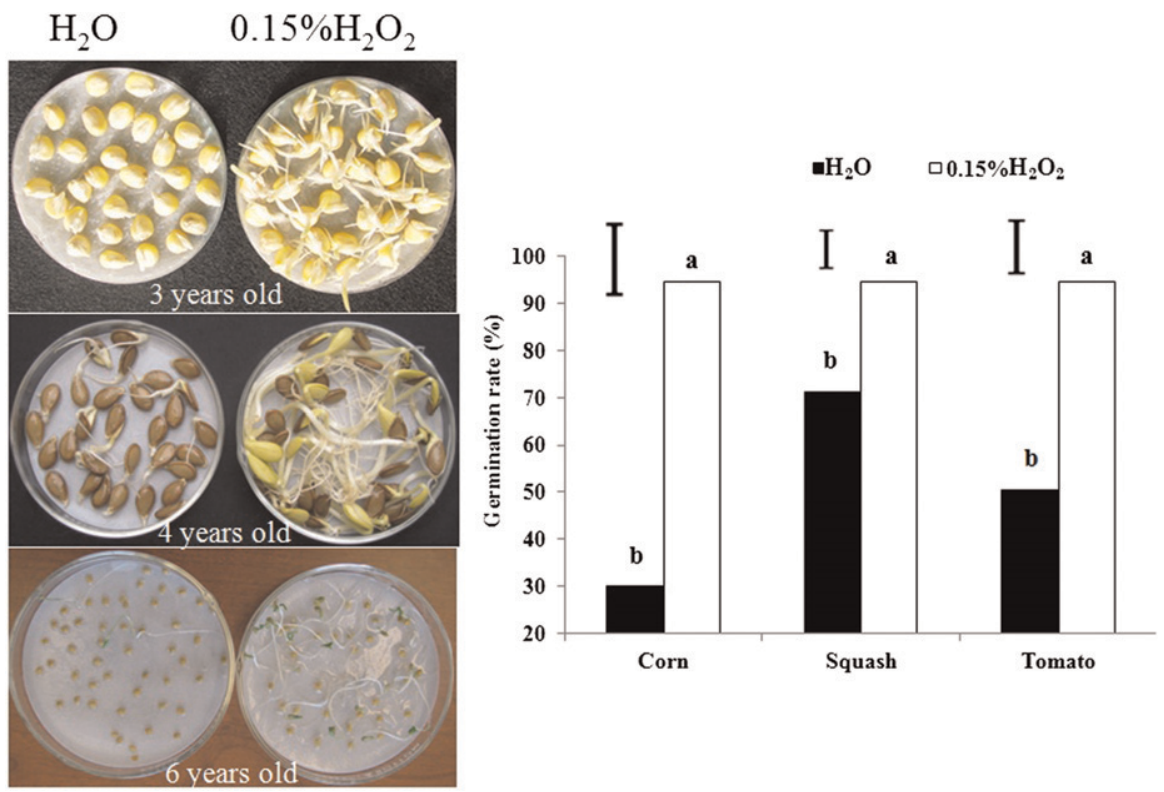

Fig. 5. Effects of oxygen bioavailability on germination percentages of aged corn, squash, and tomato seeds. Corn seeds had been aged three years, squash seeds four years, and tomato seeds six years. Vertical bars indicate least significant difference at $\alpha=0.05$.

and pressed directly on the substrate, the ADHase activity of the embryos was almost double that of embryos of seeds with the embryo facing up to the air. In the aeroponics treatment, the seeds had been suspended in a mist and with ample air. However, the $\mathrm{H}_{2} \mathrm{O}_{2}$ treatment with concentration of $0.15 \%$ reduced the ADHase activity to $\approx 40 \%$ of that of embryos from the aeroponics treatment. At $25^{\circ} \mathrm{C}$, the dissolved oxygen level in water is only $\approx 250 \mu \mathrm{M}$. This small supply of dissolved oxygen might be consumed on the outer cell layers of the seeds. include nutrients, plant hormones, insecticides, and fungicides, but no oxygen fertilizer is included. Oxygen bioavailability is essentially ignored because oxygen in its gaseous state is not easily manipulated. Corn seeds have a relatively large size and a relatively small specific surface area. A small specific surface area of a seed is not conducive to obtaining sufficient oxygen when the seed germinates. The data from this study proved that bioavailable oxygen is crucial for seeds to imbibe and germinate regardless of vegetable species (Figs. 1 through 9). Particularly, embryos consumed much more oxygen than endosperms. This phenomenon indicates that embryos metabolize faster than endosperms regardless of the bioavailability of oxygen because an embryo is a metabolic center. Therefore, the oxygen component should be added to seed coatings because better oxygen bioavailability improves vigor and germination of seeds. Sufficient bioavailable oxygen is helpful in resisting pathogens and fostering seedling establishment (Lynch et al., 1981), which may lead to larger harvests. In addition, an oxygen component would make possible the use of seed that had been held in long-term storage. Finally, an oxygen component may facilitate rescuing the germplasm of very old seeds (Desai, 2004), and this could be of great importance to plant breeders and curators of seed collections. For convenient manipulations, peroxides such as calcium peroxide or hydrogen peroxide may be more readily manipulated and more applicable to improved seed germination than gaseous oxygen. Clearly, seed coatings with oxygen fertilizers should be developed to improve the establishment of field populations of corn and various other large seeded crop species. This effect of oxygen bioavailability on ADHase activity means that the embryos of corn seeds, which are large relative to seeds of many other species, are vulnerable to mild hypoxia even in aeroponics. However, $0.15 \% \quad \mathrm{H}_{2} \mathrm{O}_{2}$ can supply $\approx 80$ times more bioavailable oxygen than aeroponics. This concentration of oxygen appears to be sufficient to reach all of the cells of the corn embryo. Thus, the seeds did not suffer from low-oxygen stress in the $0.15 \% \mathrm{H}_{2} \mathrm{O}_{2}$ treatment.

Oxygen bioavailability and apertures of water gates of corn seeds. Temperature, moisture, and oxygen combine to determine the basic conditions for germination of most seeds (Desai, 2004). That temperature impacts water uptake is well known. However, the result of this study proves that oxygen bioavailability also influences the imbibition rate of corn seeds. Tournaire-Roux et al. (2003) recently elucidated the whole root and cell bases for inhibition of water uptake by anoxia and linked them to cytosol acidosis. They proved that one early response of plants to oxygen deficiency is the downregulation of water uptake of roots. The present study indirectly showed that corn seeds downregulated imbibition in hypoxic stress (Fig. 6). There might be two possible reasons responsible for this. On one hand, the water channel, namely, the water gate (Holbrook and Zwieniecki, 


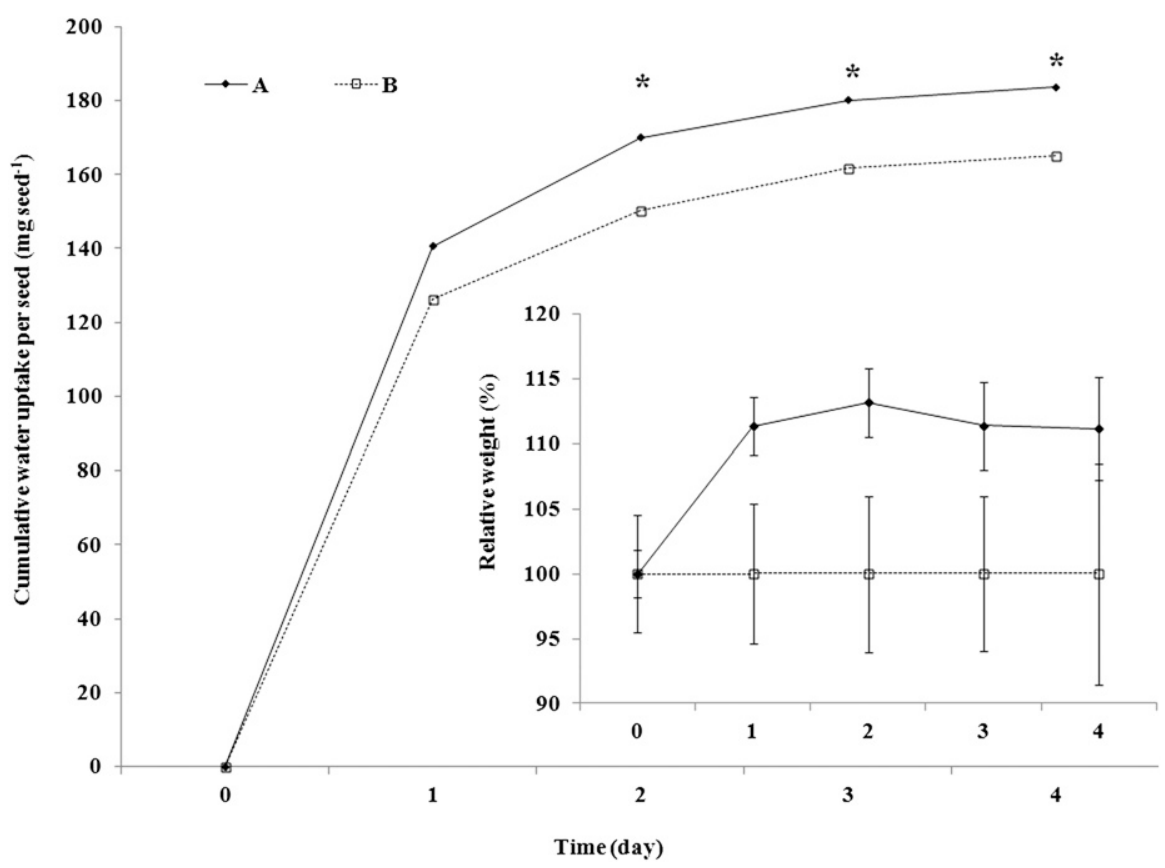

Fig. 6. Time course of imbibition of corn seed at $30{ }^{\circ} \mathrm{C}$ treated either with $0.15 \%$ hydrogen peroxide $\left(\mathrm{H}_{2} \mathrm{O}_{2}\right)$ (curve A) or with water (curve B). Weight of seeds was determined gravimetrically after unbound moisture had been removed from the seed surface. Asterisk indicates significantly $(P<0.05)$ different. Inset: Changes in relative seed weight $(\%)$ calculated by using the seed weight in the deionized water. $\mathrm{X}$ axis donates time (day).

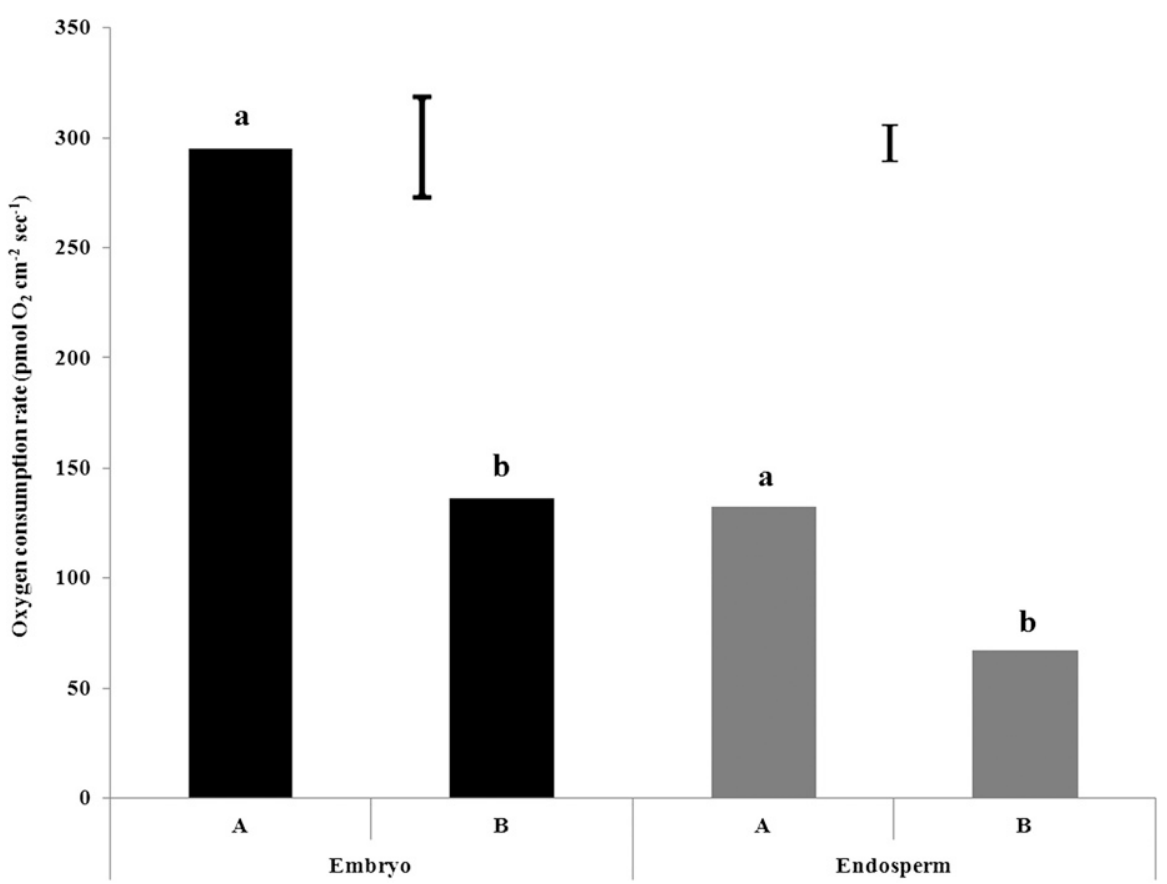

Fig. 7. Oxygen consumption rates of corn seeds that had been soaked for $24 \mathrm{~h}$ either in $0.15 \%$ hydrogen peroxide $\left(\mathrm{H}_{2} \mathrm{O}_{2}\right)(\mathbf{A})$ or in deionized (DI) water $(\mathbf{B})$. Vertical bars indicate least significant difference at $\alpha=0.05$.

2003), may have been downregulated and therefore the rate of imbibition was curtailed. Probably this downregulation is an adaptive response of plants to hypoxic stress. On the other hand, sufficient oxygen favored the normal germination of seeds and hence, the growth of seedlings, which consumed more oxygen (Fig. 7). Consequently, the seeds and $\mathrm{H}_{2} \mathrm{O}_{2}$ was $12.4 \% \pm 7.5 \%$ greater than that of the control. Again, $\mathrm{H}_{2} \mathrm{O}_{2}$ increased imbibition of corn seeds. Thus, the effect of $\mathrm{Hg}$ on seeds was different from that reported on roots, and this difference may reflect an organ-specific response to the metal ions. However, the addition of a small quantity of $\mathrm{H}_{2} \mathrm{O}_{2}$ to the water medium invariably enhanced the imbibition of the seeds. Clearly, the supply of sufficient bioavailable oxygen is an effective way to improve germination of corn seeds. Thus, provision of the appropriate concentration of bioavailable of oxygen may be a potent measure to rescue aged and/or improperly stored seeds for use in crop production, plant breeding, or maintenance of germplasm collections.

Oxygen bioavailability and cellular respiration. Every step of plant growth and development depends directly on active chemical energy, i.e., ATP. ATP in seeds is produced from decomposition of glucose including glycolysis and oxidative phosphorylation in the cellular respiration chain. Under hypoxic conditions, one mole of glucose can only generate $2 \mathrm{~mol}$ of ATP through glycosis. As a byproduct from fermentation of glucose, ethanol, which is toxic to embryos and seedlings, can be produced and accumulated (Drew, 1997). Thus, germination percentage is low. However, the same mole of glucose can produce up to $38 \mathrm{~mol}$ of ATP when there is sufficient oxygen (Rich, 2003). No ethanol can be produced under oxygen enrichment with $0.15 \% \mathrm{H}_{2} \mathrm{O}_{2}$. Hence, seed germination percentage is high and seedlings grow faster (Figs. 1 and 5). Oxygen consumption is closely related to metabolic rate. This phenomenon can be found from Figure 7. Embryos metabolize and consume oxygen faster than endosperms regardless of the bioavailability of oxygen (Fig. 8). When no $\mathrm{H}_{2} \mathrm{O}_{2}$ was included in the liquid medium, the corn seeds suffered from lack of oxygen bioavailability (Figs. 6 to 8 ).

Oxygen bioavailability has a crucial role in regulating germination of vegetable seeds. This research was conducted with seeds of corn, squash, and tomato treated with or without $\mathrm{H}_{2} \mathrm{O}_{2}$. The age of the seeds ranged from less than one year to six years. Seed germination percentages, imbibition, oxygen consumption, and ADHase activity were gravimetrically, electrochemically, and colorimetrically determined as appropriate. The best concentration of $\mathrm{H}_{2} \mathrm{O}_{2}$ to produce an excellent germination percentage is $0.15 \%$ for both aged and unaged seeds of the three tested species. The amounts of oxygen consumed by corn embryos and endosperms were significantly greater in $0.15 \% \mathrm{H}_{2} \mathrm{O}_{2}$ than in water. The ADHase activity of corn seeds with the embryo lying against the moist substrate was significantly greater than that of the seeds with the embryo facing upward in the air. Also, the ADHase activity of the corn seeds in an aeroponics treatment was significantly greater than that of the seeds treated with $0.15 \% \mathrm{H}_{2} \mathrm{O}_{2}$. Physical orientation of corn seeds had, accordingly, an important effect on the germination percentage of the corn 


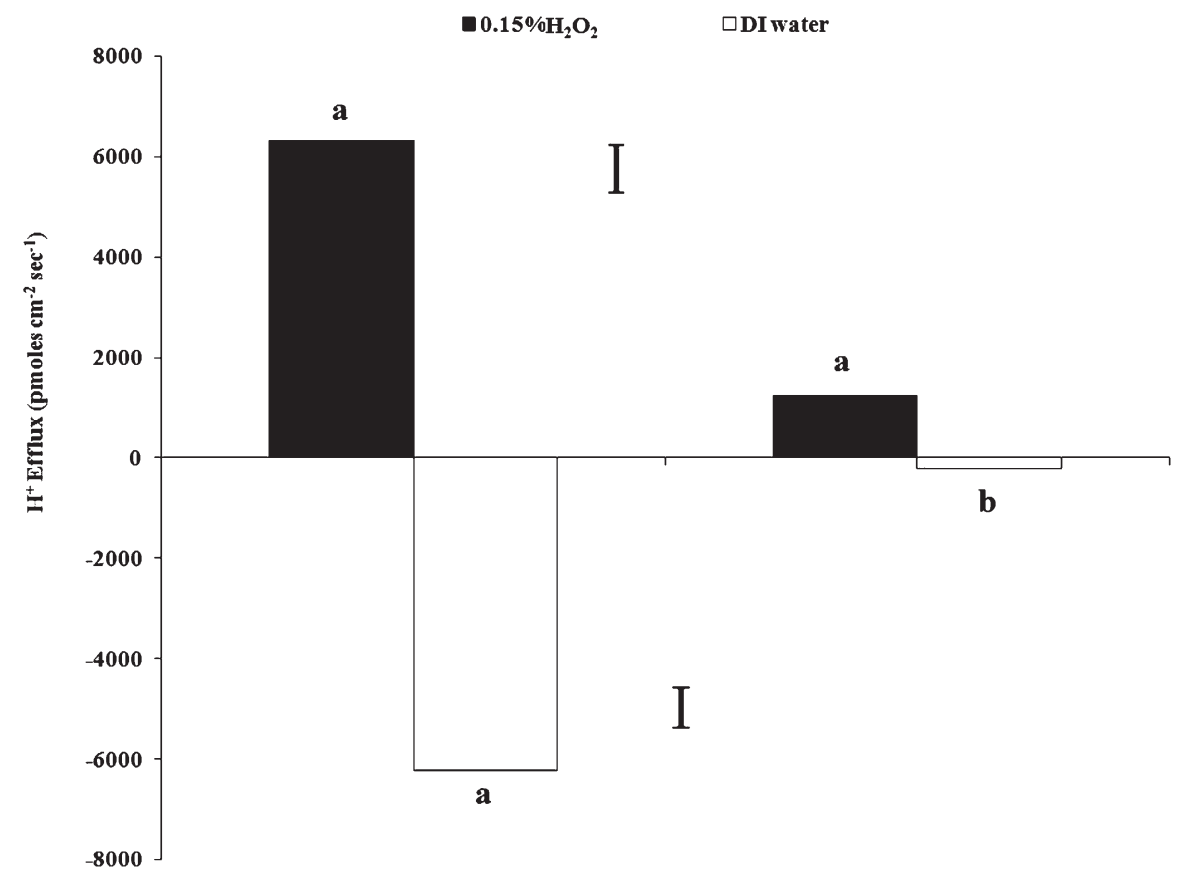

Fig. 8. Proton efflux and influx with respect to corn seed embryos and endosperms treated with either $0.15 \%$ hydrogen peroxide $\left(\mathrm{H}_{2} \mathrm{O}_{2}\right)$ or deionized (DI) water for $1 \mathrm{~d}$. The embryos had much stronger metabolism than the endosperms regardless of oxygen bioavailability and hence had much apparent proton efflux. Vertical bars indicate least significant difference at $\alpha=0.05$.

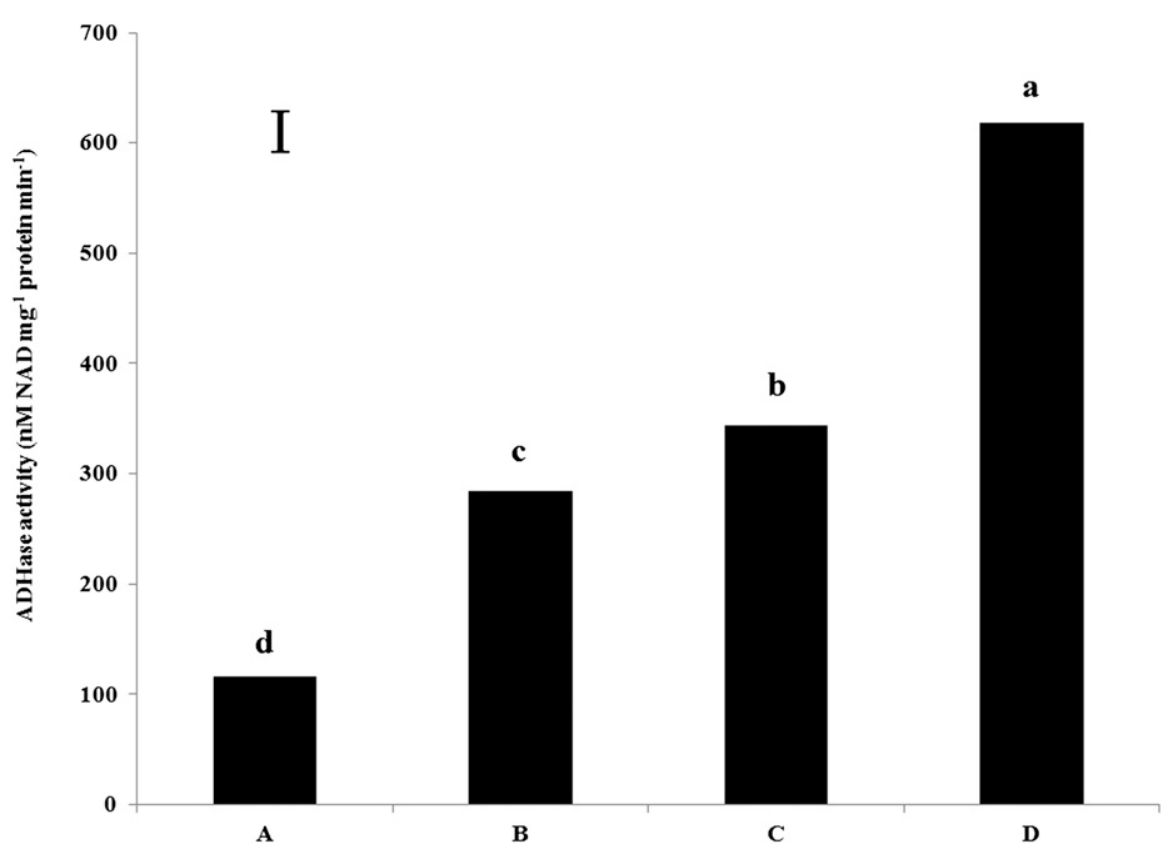

Fig. 9. Alcohol dehydrogenase (ADHase) activities in corn embryos at $48 \mathrm{~h}$ after germination and maintained in media at $25{ }^{\circ} \mathrm{C}$ with different concentrations of bioavailable oxygen. (A) $0.15 \%$ hydrogen peroxide $\left(\mathrm{H}_{2} \mathrm{O}_{2}\right)$ for $24 \mathrm{~h}$; (B) aeroponics; (C) every seed was positioned on a on a napkin saturated with $0.5 \mathrm{~mm} \mathrm{CaSO}_{4}$ solution with the embryo oriented to the top of the seed and adjacent to the air; (D) each seed was positioned with the embryo against the napkin saturated with $0.5 \mathrm{~mm} \mathrm{CaSO}_{4}$ solution. Vertical bar indicates least significant difference at $\alpha=0.05$.

seeds. The germination percentage of seeds with the embryos facing up to the air was $\approx 50 \%$ greater than that of seeds that had the embryo pressed against the underlying moist substrate. Dilute $\mathrm{H}_{2} \mathrm{O}_{2}$ greatly improved the germination percentages of the tested vegetable seeds as old as six years and which had not been stored under optimum conditions. This concentration significantly accelerated the imbibition of corn seeds and boosted seed germination. As already noted, this same concentration of $\mathrm{H}_{2} \mathrm{O}_{2}$ was highly effective in rescuing aged vegetable seeds of squash and tomato as well. Bioavailable oxygen controlled water uptake, namely, imbibition of the tested corn seeds. Oxygen fortification with dilute $\mathrm{H}_{2} \mathrm{O}_{2}$ greatly improved seed vigor and accelerated establishment of seedlings of the three tested species. Oxygen bioavailability enrichment with dilute $\mathrm{H}_{2} \mathrm{O}_{2}$ significantly increased seed germination percentage and seedling growth of the tested species and has great potential to enhance the productivity of commercial crop production.

\section{Literature Cited}

Arcan, I. and A. Yemsnicioğlu. 2007. Antioxidant activity of protein extracts from heat-treated or thermally processed chickpeas and white beans. Food Chem. 103:301-312.

Benamar, A., J. Grelet, C. Tallon, E. Teyssier, M. Renard, P. Satour, F. Duval, F. Montrichard, P. Richomme, and D. Macgerel. 2003. Some observations on seed quality and mitochondrial performance, p. 243-250. In: Nicolas, G., K.J. Bradford, D. Come, and H.W. Pritchard (eds.). The biology of seed. CABI Publishing, Cambridge, MA

Bewley, J.D. and M. Black. 1994. Seeds: Physiology of development and germination. 2nd Ed. Plenum Press, New York, NY.

Dennis, E.S., R. Dolferus, M. Ellis, M. Rahman, Y. Wu, F.U. Hoeren, A. Grover, K.P. Ismond, A.G. Good, and W.J. Peacock. 2000. Molecular strategies for improving waterlogging tolerance in plants. J. Expt. Bot. 51:89-97.

Desai, B.B. 2004. Seeds handbook: Processing and storage. 2nd Ed. Marcel Dekker, Inc., New York, NY.

Drew, M.C. 1997. Oxygen deficiency and root metabolism: Injury and acclimation under hypoxia and anoxia. Annu. Rev. Plant Physiol. Plant Mol. Biol. 48:223-250.

Edelstein, M., F. Corbineau, J. Kigel, and H. Nerson. 1995. Seed coat structure and oxygen availability control low temperature germination of melon (Cucumis melo) seeds. Physiol. Plant. 93:451-456.

Geigenberger, P., A.R. Fernie, Y. Gibon, and M. Christ. 2000. Metabolic activity decreases as an adaptive response to low internal oxygen in growing potato tubers. Biol. Chem. 381:723740.

Håkansson, I., T. Keller, J. Arvidsson, and T. Rydberg. 2012. Effects of seedbed properties on crop emergence. 4. Inhibitory effects of oxygen deficiency. Acta Agr. Scandinavica, Section B-Soil and Plant Sci. 62:166-171.

Harris, D.A. 1987. Spectrophotometric assays, p. 59-60. In: Harris, D.A. and C.L. Bashford (eds.). Spectrophotometry and spectrofluorometry. I.R.L. Press, Oxford, UK.

Holbrook, N.M. and M.A. Zwieniecki. 2003. Water gate. Nature 425:361.

Hong, F. 2001. Study on the mechanism of cerium nitrate effects on germination of aged rice seed. Biological Trace Element Research 87:191200.

Hubbard, M.R. 2001. Statistical quality control for the food industry. 2nd Ed. Aspen Publishers, Inc., Gaithersburg, MD

Jackson, M.B., K. Ishizawa, and O. Ito. 2009. Evolution and mechanisms of plant tolerance to flooding stress. Ann. Bot. (Lond.) 103:137142.

Lide, D.R. 1998. Handbook of chemistry and physics. CRC Press, Boca Raton, FL.

Lowry, O.H., N.J. Rosebrough, A.L. Farr, and R.J. Randall. 1951. Protein measurement with the Folin phenol reagent. J. Biol. Chem. 193:265275.

HortScience Vol. 47(12) December 2012 
Lynch, J., G.R. Cramer, and A. Lauchli. 1987. Salinity reduces membrane-associated calcium in corn root protoplasts. Plant Physiol. 83:390-394.

Lynch, J.M., S.H.T. Harper, and M. Sladdin. 1981. Alleviation, by a formulation containing calcium peroxide and lime, of microbial inhibition of cereal seedling establishment. Curr. Microbiol. 15:27-30.

Maurel, C. 1997. Aquaporins and water permeability of plant membranes. Annu. Rev. Plant Physiol. Plant Mol. Biol. 48:399-429.

Nadeem, M., A. Mollier, C. Morel, A. Vives, L. Prud'homme, and S. Pellerin. 2012. Maize (Zea mays L.) endogenous seed phosphorus remobilization is not influenced by exogenous phosphorus availability during germination and early growth stages. Plant soil. <http://www. springerlink.com/content/b747127159k36g82/>.

Peterson, G. 1977. A simplification of the protein assay method of Lowry et al. which is more generally applicable. Anal. Biochem. 83:346356.

Rich, P.R. 2003. The molecular machinery of Keilin's respiratory chain. Biochem. Soc. Trans. 31:1095-1105.

SAS Institute. 2009. SAS/STAT user's guide. Version 9.1.3. SAS Inst., Cary, NC.

Smith, P.J.S., K. Hammar, D.M. Porterfield, R.H. Sanger, and J.R. Trimarchi. 1999. Self-referencing, non-invasive, ion selective electrode for single cell detection of trans-plasma membrane. Microsc. Res. Tech. 46:398-417.

Sowa, A.W., S.M.G. Duff, P.A. Guy, and R.D. Hill. 1998. Altering hemoglobin levels changes energy status in maize cells under hypoxia. Proc. Natl. Acad. Sci. USA 95:10317-10321.

Sveinsdottir, H., F. Yan, Y. Zhu, T. Peiter-Volk, and S. Schubert. 2009. Seed ageing-induced inhibition of germination and post-germination root growth is related to lower activity of plasma membrane $\mathrm{H}^{+}$-ATPase in maize roots. J. Plant Physiol. 166:128-135.

Tournaire-Roux, C., M. Sutka, H. Javot, E. Guout, P. Gerbeau, D.T. Luu, R. Bligny, and C. Maurel. 2003. Cytosolic $\mathrm{pH}$ regulates root water transport during anoxic stress through gating of aquaporins. Nature 425:393-397.

Wu, F.H., G.C. Zhao, and X.W. Wei. 2002. Electrocatalytic oxidation of nitric oxide at multi-walled carbon nanotubes modified electrode. Electrochem. Commun. 4:690-694.

Xie, Y. and R. Wu. 1989. Rice alcohol dehydrogenase genes: Anaerobic induction, organ specific expression and characterization of cDNA clones. Plant Mol. Biol. 13:53-68.

Yan, F., R. Feuerle, S. Schaffer, H. Fortmeier, and S. Schubert. 1998. Adaptation of active proton pumping and plasmalemma ATPase activity of corn roots to low root medium $\mathrm{pH}$. Plant Physiol. 117:311-319. 